\title{
Differences in pollination success between local and foreign flower color phenotypes: a translocation experiment with Gentiana lutea (Gentianaceae)
}

\author{
Javier A Guitián ${ }^{\text {Corresp.. }}{ }^{1}$ ， Mar Sobral ${ }^{2}$, Tania Veiga ${ }^{1}$ ， María Losada ${ }^{\text {Corresp.. }}{ }^{2}$ ， Pablo Guitián ${ }^{1}$, José M Guitián ${ }^{2}$ \\ 1 Departamento de Botánica/Facultade de Bioloxía, Universidad de Santiago de Compostela, Santiago de Compostela, A Coruña, Spain \\ 2 Departamento de Bioloxía celular e Ecoloxía/Facultade de Bioloxía, Universidad de Santiago de Compostela, Santiago de Compostela, A Coruña, Spain \\ Corresponding Authors: Javier A Guitián, María Losada \\ Email address: javier.guitian@usc.es, maria.cuquexo@gmail.com
}

Background. The adaptive maintenance of flower color variation is frequently attributed to pollinators partly because they preferentially visit certain flower phenotypes. We tested whether Gentiana lutea which shows a flower color variation (from orange to yellow) in the Cantabrian Mountains range (north of Spain) - is locally adapted to the pollinator community.

Methods. We transplanted orange-flowering individuals to a population with yellow-flowering individuals and vice versa, in order to assess whether there is a pollination advantage in the local morph by comparing its visitation rate with the foreign morph.

Results. Our reciprocal transplant experiment did not show clear local morph advantage in overall visitation rate: local orange flowers received more visits than foreign yellow flowers in the orange population, while both local and foreign flowers received the same visits in the yellow population; thus, there is no evidence of local adaptation in Gentiana lutea to the pollinator assemblage. However, some floral visitor groups (such as Bombus pratorum, B. soroensis ancaricus and B. lapidarius decipiens) consistently preferred the local morph to the foreign morph whereas others (such as Bombus terrestris) consistently preferred the foreign morph.

Discussion. We concluded that there is no evidence of local adaptation to the pollinator community in each of the two $G$. lutea populations studied. The consequences for local adaptation to pollinator on $G$. lutea flower color would depend on the variation along the Cantabrian Mountains range in morph frequency and pollinator community composition. 
1 Differences in pollination success between local and foreign flower color phenotypes: a

2 translocation experiment with Gentiana lutea (Gentianaceae)

3 Javier Guitián ${ }^{1}$, Mar Sobral $^{2}$, Tania Veiga ${ }^{1}$, María Losada $^{2}$, Pablo Guitián ${ }^{1}$ and José Guitián ${ }^{2}$

$4 \quad{ }^{1}$ Departamento de Botánica/Facultade de Bioloxía, Universidade de Santiago de

5 Compostela, 15782 Santiago de Compostela, Spain.

$6 \quad{ }^{2}$ Departamento de Bioloxía celular e Ecoloxía/Facultade de Bioloxía, Universidad de Santiago

7 de Compostela, 15782 Santiago de Compostela, Spain.

9 Corresponding Author:

10 Javier Guitián

11 Departamento de Botánica/Facultade de Bioloxía, Universidade de Santiago de Compostela, 1215782 Santiago de Compostela, Spain.

13 Email address: javier.guitian@usc.es 


\section{Abstract}

27 Background. The adaptive maintenance of flower color variation is frequently attributed to pollinators partly because they preferentially visit certain flower phenotypes. We tested whether Gentiana lutea - which shows a flower color variation (from orange to yellow) in the Cantabrian Mountains range (north of Spain) - is locally adapted to the pollinator community.

31 Methods. We transplanted orange-flowering individuals to a population with yellow-flowering

32 individuals and vice versa, in order to assess whether there is a pollination advantage in the local 33 morph by comparing its visitation rate with the foreign morph.

34 Results. Our reciprocal transplant experiment did not show clear local morph advantage in 35 overall visitation rate: local orange flowers received more visits than foreign yellow flowers in 36 the orange population, while both local and foreign flowers received the same visits in the yellow 37 population; thus, there is no evidence of local adaptation in Gentiana lutea to the pollinator assemblage. However, some floral visitor groups (such as Bombus pratorum, B. soroensis ancaricus and B. lapidarius decipiens) consistently preferred the local morph to the foreign morph whereas others (such as Bombus terrestris) consistently preferred the foreign morph.

41 Discussion. We concluded that there is no evidence of local adaptation to the pollinator 42 community in each of the two G. lutea populations studied. The consequences for local 43 adaptation to pollinator on $G$. lutea flower color would depend on the variation along the 44 Cantabrian Mountains range in morph frequency and pollinator community composition. 45 
46 Key words: Flower color variation, Local adaptation, Pollinator preferences, Reciprocal

47 transplants, Gentiana lutea

48

49

\section{Introduction}

51 Floral evolution is primarily driven by pollinators (Bradshaw \& Schemske, 2003; Whittall \&

52 Hodges, 2007). The diversity in floral traits found in angiosperms, such as flower color, could be

53 related with transitions in these traits (Rausher, 2008), as a result of different selective pressures

54 exerted by pollinators with strong preferences for certain characteristics (Schemske \& Bradshaw, 55 1999; Streisfeld \& Kohn, 2007) or by changes in pollinator community composition (Ellis \&

56 Johnson, 2009). Thus, floral diversification and speciation among closely related plant

57 populations may result from the isolation and/or local adaptation to the most efficient pollinators,

58 which increase the number of visits per plant depending on their flower preferences (Harder \&

59 Johnson, 2009; and references therein).

60

61 The adaptive maintenance of flower color variation is frequently attributed to pollinators, in part

62 because they tend to promote assortative mating, i.e. preferentially visiting certain phenotypes

63 (Waser \& Price, 1981; Stanton, 1987; Jones \& Reithel, 2001). However, many other reasons

64 could explain the evolution of floral diversification, such as the potential uncoupling of the

65 evolution of floral traits from pollinator-mediated selection (Strauss \& Whittall, 2006). For

66 example, pleiotropic effects on the biosynthetic pathways of floral pigmentation may drive the

67 evolution to alternative flower colors (Armbruster, 1993; Schemske \& Bierzychudek, 2007;

68 Cooley, Carvallo \& Willis, 2008). 
69

70 Many studies support that animal pollinator preferences may cause selective pressures on flower

71 color, which may fluctuate depending on the structure and/or composition of the pollinator

72 community (Melendez-Ackerman \& Campbell, 1998; Gómez \& Zamora, 2000). In this context,

73 reciprocal transplant experiments between populations can be a powerful tool to assess how

74 changes in flower color preferences of the pollinator assemblage contribute to an adaptive

75 advantage of the local morph over the foreign morphs (Streisfeld \& Kohn, 2007).

76

77 Gentiana lutea L. shows flower color variation along the Cantabrian Mountains (Northern

78 Spain). Gentiana lutea flowers are typically yellow (G. lutea var. lutea), though northwest

79 Iberian populations have orange-flowering individuals, which constitutes a different variety of

80 the species (G. lutea var. aurantiaca; Renobales, 2012). The pollinator assemblages are made up

81 mostly of bumblebee species (Veiga et al., 2015; Sobral et al., 2015). Previous studies conclude

82 that: (i) Gentiana lutea flower color variation does not result from adaptation to environmental

83 factors, such as elevation, temperature, radiation, and precipitation (Veiga et al., 2016); (ii)

84 Gentiana lutea is strongly dependent on pollinators for reproduction, and the plant has a positive

85 relationship between the number of pollinator visits and the number of seeds it produces (Losada

86 et al., 2015); (iii) there is a partial hybridization barrier among G. lutea color morphs (Losada et

87 al., 2015); (iv) Gentiana lutea flower color influences pollinator visits and its variation is related

88 to changes in pollinator community composition across populations, since part of this variation is

89 explained by different pollinator selective pressures exerted on flower color among G. lutea

90 populations (Sobral et al., 2015); and (v) the most abundant pollinators of our study species,

91 Bombus terrestris and B. pratorum (Veiga et al., 2015), possess photoreceptors with low 
92 sensitivity to red colors; but other pollinators interacting with G. lutea plants, such as Bombus

93 lapidarius, has high sensitivity to red colors despite the lack of photoreceptors required (Peitsch

94 et al., 1992).

95

96 In order to determine whether $G$. lutea populations are locally adapted to the pollinator

97 community, we evaluated the effect of local and foreign flower color morphs on pollinator

98 visitation rate by means of reciprocal transplants in two Gentiana populations. More specifically,

99 we tested whether there is an adaptive advantage in the local flower color morph relative to the

100 foreign morph in pollinator visits by comparing the (i) overall pollinator assemblage, and (ii)

101 different visitor groups separately. We predicted that the local flower color morph would receive

102 more pollinator visits than the foreign morph, and that the two different color morphs would 103 receive visits by different pollinator groups in their local populations.

\section{Material and Methods}

\section{Plant species}

107 Gentiana lutea L. is an herbaceous perennial geophyte (Fig. 1). During summer, the rhizome 108 develops a flowering stalk of ca. $80 \mathrm{~cm}$ high, with a basal rosette formed by 4-8 oblong leaves.

109 Flowers grow in two opposed cymose groups (each one with 15 flowers) at different stalk levels, 110 above two elliptic leaves; and one flower crowns the top of the stalk. Flowers feature a rotate

111 corolla with 5-7 lobules, 5-7 free stamens, and a fixed ovary with two nectaries on the base. The

112 fruit is an ovoid capsule, holding elliptic and winged seeds of 3-4 mm (Renobales, 2012). This

113 species needs pollinators - mainly bumblebees - to produce seed (see Veiga et al., 2015; Sobral 114 et al., 2015). 
116 Gentiana lutea flower color varies between orange and yellow (see Fig. 1) along the Cantabrian

117 Mountains (Northern Spain; Fig. 2). The western populations (west of Somiedo Natural Park)

118 have orange-flowering individuals, whereas the eastern populations (east of Puerto de Ventana)

119 have yellow-flowering individuals; and the intermediate populations show individuals with

120 flowers of a gradation between these two color morphs.

121

122 Study site

123 The study was conducted in July 2012 at the northwest of the Iberian Peninsula in two

124 populations, one located in Sierra de Ancares (orange-flowered population) and other in Puerto

125 del Pontón (yellow-flowered population), separated by approximately 160 km (Fig. 2).

126 Population size was estimated by the total number of $G$. lutea individuals $(>3000$ in both

127 populations).

128

129 Flower color of 75 haphazardly selected flowers (3 flowers per plant, 25 plants) was measured 130 the previous year in both populations by means of a spectrometer (USB2000+; Ocean Optics, 131 Inc., Dunedin, FL) and petal color spectra were processed using the SpectraSuite ${ }^{\circledR}$ software 132 (Ocean Optics, Inc., Dunedin, FL, USA). The CIELab Colorimetric System (CIE, 2004) was 133 chosen to describe flower color variation in the visible range of the electromagnetic spectrum, 134 through three variables reduced by principal component analysis (for additional details, see 135 Veiga et al., 2015): $L$ (brightness of color, from black to white), $a$ (red color variation, from 136 green to red) and $b$ (yellow color variation, from blue to yellow). Individuals from the Sierra de 
137 Ancares population showed orange-colored flowers $(L=16.42 ; a=11.77 ; b=23.61)$, and from

138 the Pontón population, yellow ones $(L=19.64 ; a=3.84 ; b=27.84)$.

139

140 Although certain pollinator species may detect UV light, a previous study found no differences

141 among G. lutea populations and between individuals with different color morphs (orange or

142 yellow, discernible by human eye) in the UV light range (Veiga et al., 2015). Thus, we presume

143 that UV light does not drive local adaptation among populations, and consider flower color in

144 both, the UV and visible light ranges in this study.

145

\section{Experimental design}

147 In July 2012, a reciprocal transplant experiment was conducted to analyze local adaptation of 148 color morphs to pollinator assemblage of both populations (thanks to the field permission issued 149 by the Environmental Territorial Service institution from León, Regional Government of Castilla 150 and León, Territorial Delegation of Government of Spain - Identifier:

151 12_LE_325_RNA_PuebladeLilio_INV - Reference: 06.01.013.016/ROT/abp - File number:

$152 \mathrm{AEN} / \mathrm{LE} / 103 / 12)$. Given the difficulty of transplanting plants in pots due to their extensive

153 rhizomes, flowering stems used for the experiment were cut at the height of rhizome, placed in

154 plastic containers with water $(0.5 \mathrm{~L})$, sealed with adhesive tape, and buried at ground level to 155 prevent evaporation and ensure longer flower life. The effectiveness of this method was

156 previously determined by checking the duration of flowering and pollination in a control 157 population and verifying that the flowers were well-preserved in the first four days. 
159 For the reciprocal transplant experiment, 15 flowering stems were cut in the orange population

160 (Ancares) and transferred to the yellow population (Pontón) immediately after collection, while

161 simultaneously, 15 yellow stems were cut in Pontón and transferred to the Ancares population

162 (foreign transplant treatment). Additionally, 15 plants of each population (orange in Ancares and

163 yellow in Pontón) were subjected to the same procedures (cut, transplanted, and buried) for the

164 local transplant treatment.

165

166 The same day, plant containers were placed in each population within $1 \mathrm{~m}^{2}$ squares, set in

167 random layout by picking the grid point using a random number table. Additionally, 15 plants

168 were haphazardly marked to serve as a control in both populations. Thus, each population

169 contained 30 experimental plants and 15 control plants (45 plants per population, 90 plants

170 overall). Note that the stem height, the number of floral whorls per inflorescence, and the number

171 of flowers were measured in all plant individuals to correct for possible plant morphological

172 effects in the experimental results.

173

174 Pollinator censuses

175 We conducted 15 2-minute pollinator censuses on each of the 45 plants in both flower color 176 morph populations over 3 days. According to previous studies, the observation sampling effort

177 (30 minutes per plant, 1350 minutes in each population) is appropriate to obtain an adequate

178 representation of the pollinator spectra of this species and in this geographic area (see Materials

179 and Methods section in Veiga et al., 2015; Sobral et al., 2015). For each census, the species that

180 accessed the flowers and the number of flowers they visited were recorded. 
182 Every day and before the census, the number of open flowers on each plant was counted to 183 correct for the effect of floral display in pollinator attraction. Plant censuses were randomly 184 conducted under sunny conditions between 0800 and 1800 hours. The number of visits per plant 185 (visitation rate per $30 \mathrm{~min}$ ) was used as a measure of pollination success.

186

187 At the end of each census, a sample of pollinator taxa observed was collected and sent for further 188 identification by entomological specialists from the University of Oviedo (Spain). Correcting any 189 discrepancies between our visual identifications of bumblebee species and the lab 190 determinations, species were grouped for analyses into eight morphological categories based on 191 proboscis length (Obeso, 1992). The eight morphological groups were: group 1 (Bombus 192 terrestris, B. lucorum); group 2 (B. hortorum, B. jonellus); group 3 (B. pratorum, B. soroensis 193 ancaricus, B. lapidarius decipiens); group 4 (B. wulflenii); group 5 (B. mesomelas); group 6 (B. 194 pascuorum); group 7 (B. (Psithyrus) rupestris); group 8 (B. hypnorum).

Statistical analyses

197 Several generalized linear models (GLM) were performed, where the number of visits per plant 198 was the dependent variable. The locality (Ancares and Pontón), treatment (control, local 199 transplant, and foreign transplant), pollinator group (described earlier), and the interactions 200 among these factors were included as fixed effects. The models were performed for all pollinator 201 species pooled together and for each of the eight pollinator groups independently. Residuals of 202 the dependent variable were fitted in all models with a Poisson distribution and a logarithmic 203 link function. 
205 Additionally, pairswise contrasts were performed to analyze the differences on the visitation rate 206 (number of visits per plant per $30 \mathrm{~min}$ ) by the eight bumblebee groups between and within the

207 transplant treatments and control group averaged for both destination localities. To test for local

208 adaptation, the mean differences on visitation rate of group 1 and 3 bumblebees (the most

209 abundant groups) were compared between each pair of treatments applied for the translocation

210 experiment (foreign transplants, local transplants, controls), considering both localities (Ancares

211 and Pontón). All analyses were performed using SPSS Statistics 20 (IBM Corp., Somers, NY).

212

213 Results

214 Pollinator censuses

215 In total 951 insects (99\% bumblebees belonging to the genus Bombus, and the remaining $1 \%$

216 belongs to the genus Apis or the family Vespidae) visited the plants (538 in Ancares, and 413 in

217 Pontón), which represented 3268 total cumulative flower visits (see Supplementary file,

218 Supplemental [Data] S[1]). Bombus terrestris (group 1) and Bombus pratorum (group 3) were

219 the main flower visitor of Gentiana lutea plants in Pontón, with 447 and 372 total cumulative

220 visits respectively for each group (excluding control treatment, see Fig. 3). Bombus soroensis

221 ancaricus + Bombus lapidarius decipiens (group 3) and Bombus (Psithyrus) rupestris (group 7)

222 were the main flower visitors in Ancares (338 and 224 total cumulative visits respectively for

223 each group, only for transplant treatments), being the latest group absent in Pontón, and Bombus

224 hypnorum (group 8) was only present in this location (Fig. 3).

225

226 Reciprocal transplants 
227 In Ancares, a population of orange morphs, more visits per 30 min were observed to orange- than

228 to yellow- flowering plants (32.5\% versus $24.7 \%$ plants visited, respectively for each color

229 morph); whereas in Pontón, a population consisting of yellow flowers, there was no difference in

230 visitation rate between the two morphs (39.2\% versus $41 \%$ plants visited, respectively for yellow

231 and orange morphs; see Supplemental [Data] S[2]). Number of visits per plant depended on the

232 floral visitor group $(P<0.001$; Table 1). Additionally, the number of visits per plant by floral

233 visitor groups were affected differently per treatment: control, local transplant, and foreign

234 transplant (as suggested by the significant treatment*floral visitors interaction; $P<0.05$; Table

235 1), and also by locality (as suggested by the significant treatment*floral visitors*locality

236 interaction; $P<0.05 ;$ Table 1).

237

238 Results of the GLM to analyze the locality and treatment effects on the number of visits per plant

239 for each pollinator group showed different flower color preferences, but only in the groups $1(B$.

240 terrestris) and 3 (B. pratorum, B. soroensis ancaricus + B. lapidarius decipiens; significant

241 treatment factor; group 1: $P<0.05$; group 3: $P<0.01$; Table 2). Group 1 and group 3 pollinators

242 visited control and local plants similarly in both color morph populations (Table 3; Fig. 4).

243

244 Group 1 visited foreign transplant individuals more often than local transplant individuals,

245 considering both locations (significant mean differences between foreign and local transplants; $P$

$246<0.05$; Table 3). Group 1 pollinators visited control and local plants similarly in both color

247 morph populations (Table 3; Fig. 4a). However, the absolute number of visits by these

248 pollinators was higher in Pontón (yellow morph population) than in Ancares (orange morph

249 population). 
251 Group 3 visited local transplants more often than foreign transplants in both locations (no

252 significant treatment*locality interaction; Table 2). The number of visits by group 3

253 to control and foreign plants was equal considering both populations (Table 3; Fig. 4b). Once

254 again, the absolute number of visits by these pollinators was higher in Pontón (yellow-flowered 255 population) than in Ancares (orange-flowered population).

256

\section{Discussion}

258 Our results show that Gentiana lutea plants from both locations face different sets of flower 259 visitors with different color preferences - indicated by differences in visitation rate - suggesting 260 that these differences may play a role in floral color divergence patterns. We found that the 261 orange-flowering plants may be locally adapted to the pollinator assemblage since they received

262 more visits than the yellow-flowering transplants in Ancares, the population of orange morphs.

263 However, we found no evidence of local adaptation of yellow-flowering plants to the original

264 population since the number of bumblebee visits was similar to the orange-flowering transplants

265 in Pontón. This result differs from previous research, which suggested that flower color variation 266 among $G$. lutea populations is related to selective pressures exerted by different pollinator 267 assemblages (Sobral et al., 2015).

268

269 Several possible explanations may help to clarify our findings. The different responses obtained 270 in the Ancares and Pontón populations are likely due to variation in the pollinator assemblage 271 and/or floral visitor preferences between the two areas (as experimentally demonstrated, Jones \& 272 Reithel, 2001). Ancares and Pontón have different pollinator assemblage and the species from 
273 the Ancares population may prefer local orange-flowering plants, while the species from Pontón

274 population clearly show no preference for one of the two color morphs. Geographic variation in

275 floral visitor preferences can result from changes in pollinator composition, abundance, and

276 diversity (Price et al., 2005), even different plant populations that share the same pollinator

277 group receive different proportions of flower visits from each species or functional group

278 (Fenster et al., 2004; Tastard et al., 2014). Thus, pollinator-dependent foraging preferences may

279 cause shifts in the optimal floral phenotypes (see Gómez et al., 2009; and references therein).

280

281 Within the pool of G. lutea flower visitors in the Ancares population, the most abundant species

282 (Bombus terrestris) has low sensitivity for red color detection (Peitsch et al., 1992; Briscoe \&

283 Chittka, 2001), which probably explains the reduction in this species visitation rate when

284 increasing orange-flowering individuals (Fig. 4a). We suspect that other pollinator species with

285 probably higher sensitivity to red color may increase fitness of the orange-flowering plants.

286 Therefore, the fact that they perceive red color does not imply that they necessarily would prefer

287 this color over others. In fact, B. lapidarius, present in other orange G. lutea populations

288 (personal observations), shows sensitivity for red colors; although it lacks red color receptors

289 (Kugler, 1943; Peitsch et al., 1992). If pollinator species with a higher sensitivity or innate

290 preferences for red colors are present, orange-flowered plants would increase their fitness

291 through the rising visitation rate by these pollinators. Therefore, variation of the pollinator

292 community composition might affect the selective pressures exerted on G. lutea flower color,

293 and ultimately affect flower color variation among populations via local adaptation. 
295 A second explanation is that the preference of certain pollinator groups could be dependent on

296 the frequency of each morph in the population (i.e. the preferences for orange plants in Ancares

297 are diluted in a context of yellow plants in Pontón). Empirical studies that examine plant species

298 polymorphisms in flower color, morphology, or sex phenotype generally show negative

299 frequency dependence (see references in Harder \& Johnson, 2009). However, in some cases this

300 selection occurred somewhat heterogeneously and studies have found that common (or highly

301 efficient) pollinators tend to exhibit positive frequency-dependent foraging, while less common

302 (or less efficient) species might exhibit negative frequency-dependence (Eckhart et al., 2006) or

303 positive frequency-dependence (Malerba \& Nattero, 2012).

304

305 Our results show that differences in visitation rate between Ancares and Pontón populations 306 depend on floral visitors from Groups 1 and 3. Group 1 (B. terrestris) shows preferences for the

307 least abundant morph in the population (orange in Pontón; negative frecuency-dependence).

308 Conversely, Group 3 shows a preference for the most abundant morph (orange in Ancares;

309 positive frequency-dependence). Consequently, the preference of certain pollinator groups is

310 dependent on the frequency of each morph in a population (Smithson \& Macnair, 1996). Theory

311 suggests that competition for floral resources might favor frequency-dependent foraging by some

312 pollinator species, possibly contributing to the maintenance of flower color variation by

313 frequency-dependent selection (Gigord, Macnair \& Smithson, 2001; Eckhart et al., 2006).

315 Additionally, data from this work and previous studies show that the different pollinator

316 abundance, especially groups 1 and 3, varies between years in Ancares and Pontón populations,

317 but not selective pressures exerted on G. lutea flower color (see Sobral et al., 2015). However, 
318 the pollinator assemblage composition can also vary substantially year-to-year (e.g. Herrera,

319 1988; Price et al., 2005). Bumblebee foraging may differ among years (Teräs, 1985), among sites

320 (Elam \& Linhart, 1988; Jones \& Reithel, 2001) and between queens and workers (Teräs, 1985;

321 Wesselingh \& Arnold, 2000). The floral color choices of bumblebees appear not to be governed

322 by innate preference only, but also by environment conditions and colors of co-flowering plants

323 (Teräs, 1985). Consequently, preferences for different color morphs may change temporally

324 according to the community composition, generating a mosaic of selective pressures on floral

325 color. Therefore, further analyses considering data from multiple years are needed to clearly

326 support the hypothesis of flower color adaptation to local pollinator assemblages, even though

327 possible technical and logistical challenges that would lead to the long-term monitoring of the

328 transplant experiment.

329

330 In conclusion, the present study suggests no clear evidences of local adaptation to the pollinator

331 community in each of the two G. lutea populations studied, even though some floral visitor

332 groups (such as Bombus pratorum, B. soroensis ancaricus and B. lapidarius decipiens)

333 consistently preferred the local morph to the foreign morph whereas others (such as Bombus

334 terrestris) consistently preferred the foreign morph. Variation in pollinators foraging preference

335 and visitation rate could generate a mosaic of frequency-dependent selection in $G$. lutea along

336 the Cantabrian Mountains range. The consequences for local adaptation on G. lutea flower color

337 would thus depend on variation in morph frequency, pollinator community composition and their 338 effects on plant fitness.

\section{Acknowledgements}


341 We are grateful to Paula Domínguez for the help in field work, Emilie Ploquin and José Ramón

342 Obeso (University of Oviedo, Spain) for determining the bumblebee species, Brais Losada for

343 the polishing edition of this manuscript. Luis Guitián drew the map of Figure 2. We would like

344 to thank the two anonymous reviewers for their suggestions and comments.

345

346 References

347 Armbruster WS. 1993. Evolution of plant pollination systems - hypotheses and tests with the 348 neotropical vine Dalechampia. Evolution 47: 1480-1505.

349 Bradshaw HD, Schemske DW. 2003. Allele substitution at a flower colour locus produces a 350 pollinator shift in monkeyflowers. Nature 426: 176-178. DOI: 10.1038/nature02106.

351 Briscoe AD, Chittka L. 2001. The evolution of color vision in insects. Annual Review of 352 Entomology 46: 471-510.

353 CIE P. 2004. 15: 2004. Colorimetry. Vienna: CIE Central Bureau, Austria.

354 Cooley AM, Carvallo G, Willis JH. 2008. Is floral diversification associated with pollinator 355 divergence? Flower shape, flower colour and pollinator preference in Chilean Mimulus. Annals 356 of Botany 101: 641-650.

357 Eckhart VM, Rushing NS, Hart GM, Hansen JD. 2006. Frequency-dependent pollinator 358 foraging in polymorphic Clarkia xantiana ssp. xantiana populations: implications for flower 359 colour evolution and pollinator interactions. Oikos 112: 412-421.

360 Elam DR, Linhart YB. 1988. Pollination and seed production in Ipomopsis aggregata:

361 differences among and within flower color morphs. The American Journal of Botany 75: $362 \quad 1262-1274$. 
363 Ellis AG, Johnson SD. 2009. The evolution of floral variation without pollinator shifts in

364 Gorteria diffusa (Asteraceae). The American Journal of Botany 96: 793-801. DOI:

$36510.3732 / a j b .0800222$.

366 Fenster CB, Armbruster WS, Wilson P, Dudash MR, Thomson JD. 2004. Pollination

367 syndromes and floral specialization. Annual Review of Ecology, Evolution, and Systematics 35 :

$368 \quad 375-403$.

369 Gigord LDB, Macnair MR, Smithson A. 2001. Negative frequency-dependent selection

370 maintains a dramatic flower color polymorphism in the rewardless orchid Dactylorhiza

371 sambucina (L.). Proceedings of the National Academy of Sciences (USA) 98: 6253-6255.

372 Gómez JM, Zamora R. 2000. Geographic mosaic in the evolving interactions of

373 Hormathophylla spinosa: spatial variation in the effect of pollinators and herbivores. The

374 American Naturalist 155: 657-668.

375 Gómez JM, Perfectti F, Bosch J, Camacho JPM. 2009. A geographic selection mosaic in a 376 generalized plant-pollinator-herbivore system. Ecological Monographs 79: 245-263.

377 Harder LD, Johnson SD. 2009. Darwin's beautiful contrivances: evolutionary and functional 378 evidence for floral adaptation. New Phytologist 183: 530-545.

379 Herrera C. 1988. Variation in mutualisms: the spatiotemporal mosaic of a pollinator 380 assemblage. Biological Journal of the Linnean Society 35: 95-125.

381 IBM Corp. Released 2011. IBM SPSS Statistics for Windows, Version 20.0. Armonk, NY: IBM 382 Corp.

383 Jones KN, Reithel JS. 2001. Pollinator-mediated selection on a flower color polymorphism in 384 experimental populations of Antirrhinum (Scrophulariaceae). The American Journal of Botany 385 88: $447-54$. 
386 Kugler H. 1943. Hummeln als blütenbesucher [Bumblebees as bloom visitors]. Ergebnisse der 387 biologie 19: 143-323. (In German)

388 Losada M, Veiga T, Guitián JA, Guitián JM, Guitián P, Sobral M. 2015. Is there a 389 hybridization barrier between Gentiana lutea color morphs? PeerJ 3: e1308. DOI:

390 10.7717/peerj.1308.

391 Malerba R, Nattero J. 2012. Pollinator response to flower color polymorphism and floral 392 display in a plant with a single-locus floral color polymorphism: consequences for plant 393 reproduction. Ecological Research 27: 377-385.

394 Melendez-Ackerman E, Campbell DR. 1998. Adaptive significance of flower color and inter395 trait correlations in an Ipomopsis hybrid zone. Evolution 52: 1293-1303.

396 Obeso JR. 1992. Geographic distribution and community structure of bumblebees in the 397 northern Iberian Peninsula. Oecologia 89: 244-252.

398 Peitsch D, Fietz A, Hertel H, de Souza J, Ventura DF, Menzel R. 1992. The spectral input 399 systems of hymenopteran insects and their receptor-based colour vision. Journal of Comparative 400 Physiology A 170: 23-40.

401 Price MV, Waser NM, Irwin RE, Campbell DR, Brody AK. 2005. Temporal and spatial 402 variation in pollination of a montane herb: a seven-year study. Ecology 86: 2106-2116.

403 Rausher MD. 2008. Evolutionary transitions in floral color. International Journal of Plant 404 Sciences 169: 7-21.

405 Renobales G. 2012. Gentiana lutea L. In: Castroviejo S, Talavera S, Andrés C, Arista M, 406 Fernández Piedra MP, Gallego MJ, Ortiz PL, Romero Zarco C, Salgueiro FJ, Silvestre S, 407 Quintanar A, eds. Flora ibérica XI: Gentianaceae-Boraginaceae [Iberian flora XI: 408 Gentianaceae-Boraginaceae]. Madrid: Real Jardín Botánico (CSIC), 10 13. (In Spanish) 
409 Schemske DW, Bierzychudek P. 2007. Spatial differentiation for flower colour in the desert 410 annual Linanthus parryae: was Wright right? Evolution 61: 2528-2543.

411 Schemske DW, Bradshaw HD. 1999. Pollinator preference and the evolution of floral traits in 412 monkeyflowers (Mimulus). Proceedings of the National Academy of Sciences (USA) 96:

$41311910-11915$.

414 Smithson A, Macnair MR. 1996. Frequency-dependent selection by pollinators: mechanisms 415 and consequences with regard to behaviour of bumblebees Bombus terrestris (L.) (Hymenoptera: 416 Apidae). Journal of Evolutionary Biology 9: 571-588.

417 Sobral M, Veiga T, Domínguez P, Guitián JA, Guitián P, Guitián JM. 2015. Selective 418 pressures explain differences in flower color among Gentiana lutea populations. PloS ONE 419 10(7): e0132522. DOI: 10.1371/journal.pone.0132522.

420 Stanton ML. 1987. Reproductive biology of petal color variants in wild populations of 421 Raphanus sativus: I. Pollinator response to color morphs. The American Journal of Botany 74(2): $422 \quad 178-187$.

423 Strauss SY, Whittall JW. 2006. Non-pollinator agents of selection on floral traits. In: Harder 424 LD, Barrett SCH, eds. Ecology and evolution of flowers. New York: Oxford University Press, $425 \quad 120-138$.

426 Streisfeld MA, Kohn JR. 2007. Environment and pollinator-mediated selection on parapatric 427 floral races of Mimulus aurantiacus. Journal of Evolutionary Biology 20: 122-132.

428 Tastard E, Andalo C, Burrus M, Gigord L, Thébaud C. 2014. Effects of floral diversity and 429 pollinator behaviour on the persistence of hybrid zones between plants sharing pollinators. Plant 430 Ecology \& Diversity 7: 391-400. 
431 Teräs I. 1985. Food plants and flower visits of bumblebees (Bombus: Hymenoptera, Apidae) in 432 southern Finland. Acta Zoologica Fennica 179: 1-120.

433 Veiga T, Guitián JA, Guitián P, Guitián JM, Sobral M. 2015. Are pollinators and seed 434 predators selective agents on flower color in Gentiana lutea? Evolutionary Ecology 29(3): 435 451-464. DOI: 10.1007/s10682-014-9751-6.

436 Veiga T, Guitián JA, Guitián P, Guitián JM, Munilla I, Sobral M. 2016. Flower colour

437 variation in the montane plant Gentiana lutea L. (Gentianaceae) is unrelated to abiotic factors. 438 Plant Ecology \& Diversity 9: 105-112. DOI: 10.1080/17550874.2015.1074626.

439 Waser NM, Price MV. 1981. Pollinator choice and stabilizing selection for flower color in 440 Delphinium nelsonii. Evolution 35: 376-390.

441 Wesselingh RA, Arnold ML. 2000. Pollinator behaviour and the evolution of Louisiana Iris 442 hybrid zones. Journal of Evolutionary Biology 13: 171-180.

443 Whittall JB, Hodges SA. 2007. Pollinator shifts drive increasingly long nectar spurs in 444 columbine flowers. Nature 447: 706-709. DOI: 10.1038/nature05857. 
446 Table 1: Results of the generalized linear model to analyze the effect of color morphs of

447 Gentiana lutea on the visitation rate (number of visits per plant per 30 min) by eight

448 bumblebee groups in two areas of Northern Spain (the orange color morph was present at

449 the Ancares site, whereas the yellow morph was present at the Pontón site).

450 We marked in bold the statistically significant factors $(P<0.05)$. Factors: locality (Ancares and

451 Pontón, orange and yellow morph population respectively); treatment (control, local transplants,

452 and foreign transplants); and floral visitor groups (group 1: Bombus terrestris, B. lucorum; group

453 2: B. hortorum, B. jonellus; group 3: B. pratorum, B. soroensis ancaricus, B. lapidarius

454 decipiens; group 4: B. wulflenii; group 5: B. mesomelas; group 6: B. pascuorum, group 7: B.

455 (Psithyrus) rupestris; group 8: B. hypnorum).

456

457

Factors $\quad$ Wald Chi-Square d.f. $P$

458

\begin{tabular}{lllll}
\hline Locality & 0.702 & 1 & 0.402
\end{tabular}

459

$\begin{array}{llll}\text { Treatment } & 0.110 & 2 & 0.946\end{array}$

460

461

$\begin{array}{llll}\text { Treatment * Locality } & 4.336 & 2 & 0.114\end{array}$

462

$\begin{array}{llll}\text { Floral visitors } & 66.548 & 3 & <\mathbf{0 . 0 0 1}\end{array}$

462

463

$\begin{array}{llll}\text { Treatment * Floral visitors } & 16.703 & 6 & \mathbf{0 . 0 1 0}\end{array}$

$\begin{array}{llll}\text { Treatment * Floral visitors * Locality } & 19.573 & 9 & \mathbf{0 . 0 2 1}\end{array}$


464 Table 2: Results of the generalized linear model to analyze the effect of locality, treatment, 465 and the corresponding interaction between both, on the visitation rate (number of visits per 466 plant per 30 min) by two bumblebee groups (group 1 and 3) in two areas of Northern Spain 467 (Ancares and Pontón, the orange and yellow morph population respectively).

468 We marked in bold the statistically significant factors $(P<0.05)$. Factors: locality (Ancares and 469 Pontón, orange and yellow morph population respectively); treatment (control, local transplants, 470 and foreign transplants); and floral visitor groups (group 1: Bombus terrestris, B. lucorum; group 471 3: B. pratorum, B. soroensis ancaricus, B. lapidarius decipiens). Note that we only included 472 results of the visitor groups that showed significant model effects (Group 1, Group 3).

473

\begin{tabular}{llccc}
\hline Floral visitors & Factors & Wald Chi-Square & d.f. & $P$ \\
& Locality & 32.222 & 1 & $<\mathbf{0 . 0 0 1}$ \\
Group 1 & Treatment & 6.181 & 2 & $\mathbf{0 . 0 4 5}$ \\
& Treatment * Locality & 0.692 & 2 & 0.707 \\
& Locality & 1.867 & 1 & 0.172 \\
Group 3 & Treatment & 16.331 & 2 & $<\mathbf{0 . 0 0 1}$ \\
& Treatment * Locality & 0.114 & 2 & 0.945 \\
& & & & \\
\end{tabular}

474

475 
476 Table 3: Results of pairwise contrasts to analyze the mean differences on the visitation rate

477 (number of visits per plant per $30 \mathrm{~min}$ ) by bumblebee groups 1 and 3 , averaged for two

478 areas of Northern Spain (Ancares and Pontón, the orange and yellow morph population

479 respectively) and per treatment (control, local transplant, foreign transplant).

480 We marked in bold the statistically significant mean differences between the pair of treatments

$481(P<0.05)$. Abbreviations: trans-local (local transplants), trans-foreign (foreign transplants) and

482 control (unmanipulated groups). Note that we only included results from pairwise contrasts that

483 showed significant mean differences between pair of treatments (i.e., pollinator groups 1 and 3 ).

484

\begin{tabular}{lllcccc}
\hline Floral visitors & \multicolumn{2}{c}{ Pair of treatments } & Mean-Difference & S.E. & d.f. & $P$ \\
& Control & Trans-foreign & -5.090 & 2.801 & 1 & 0.069 \\
& Control & Trans-local & 1.390 & 2.331 & 1 & 0.551 \\
Group 1 & Trans-foreign & Trans-local & 6.480 & 2.733 & 1 & $\mathbf{0 . 0 1 8}$ \\
& Control & Trans-foreign & 18.720 & 4.369 & 1 & $<\mathbf{0 . 0 0 1}$ \\
& Control & Trans-local & 8.210 & 4.992 & 1 & 0.100 \\
Group 3 & Trans-foreign & Trans-local & -10.510 & 3.736 & 1 & $\mathbf{0 . 0 0 5}$ \\
& & & & & & \\
\hline
\end{tabular}

485

486

487

488

489

490

491 
492

493

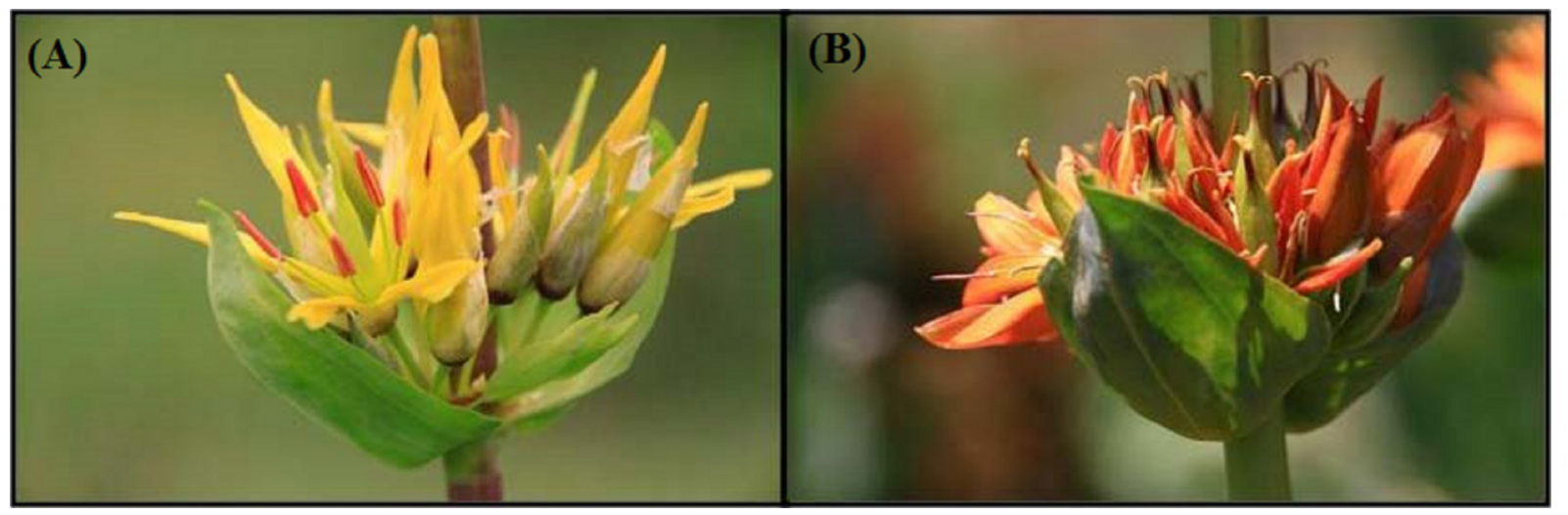

494

495 Figure 1: Color morphs of Gentiana lutea L. at northern Spain (A: var. lutea, the yellow

496 morph in Pontón location; and B: var. aurantiaca, the orange morph in Ancares location).

497 


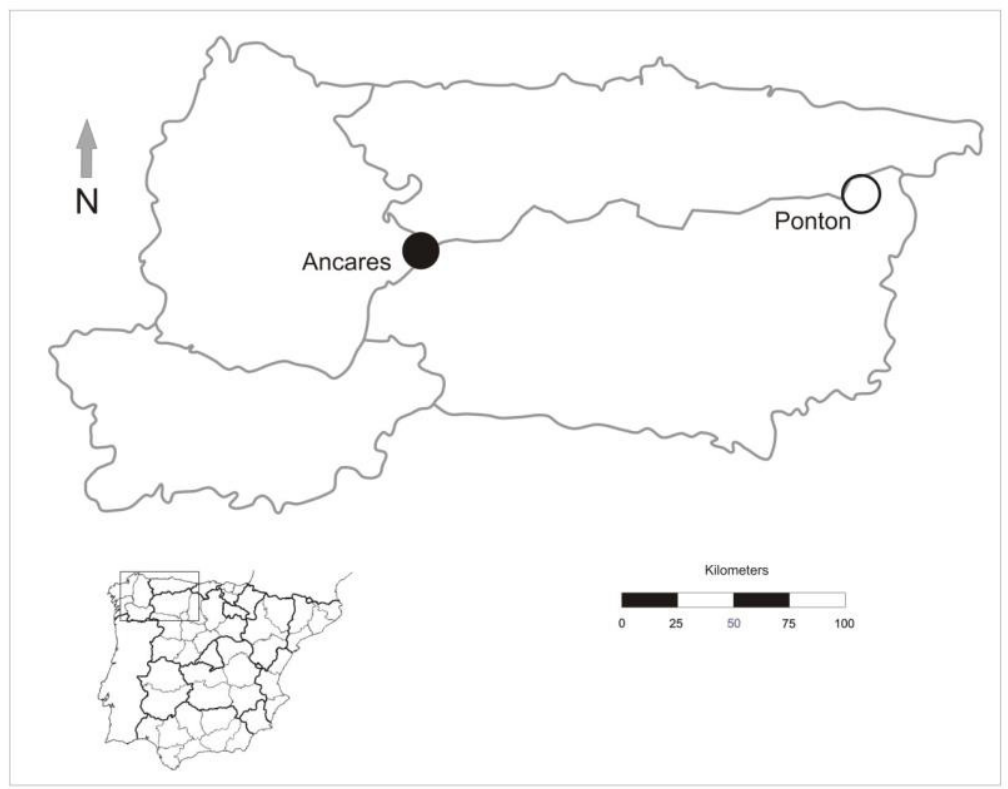

499

500 Figure 2: Geographic location of Gentiana lutea populations at northern Spain in which

501 reciprocal transplants were conducted (black dot: Ancares, the orange morph population;

502 white dot: Pontón, the yellow morph population).

503 


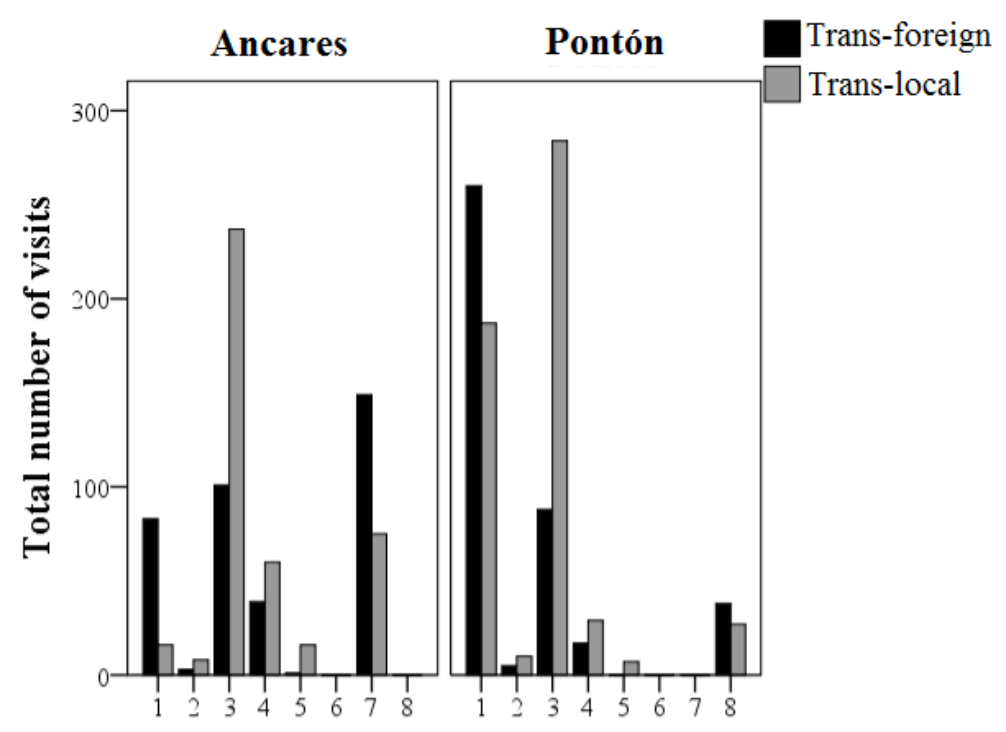

Bumblebee group

504

505 Figure 3: Total cumulative number of visits to the Gentiana lutea transplanted plants

506 (black-colored bars: foreign; grey-colored bars: local) by each group of bumblebees in the

507 two study sites at northern Spain (Ancares with the orange morph and Pontón with the

508 yellow morph).

509 Abbreviations: Trans-foreign (foreign transplant); Trans-local (local transplant). Floral visitor

510 groups were the following: group 1: Bombus terrestris, B. lucorum; group 2: B. hortorum, B.

511 jonellus; group 3: B. pratorum, B. soroensis ancaricus, B. lapidarius decipiens; group 4: B.

512 wulflenii; group 5: B. mesomelas; group 6: B. pascuorum, group 7: B. (Psithyrus) rupestris;

513 group 8: B. hypnorum.

514 
(A) Group 1 (Bombus terrestris)

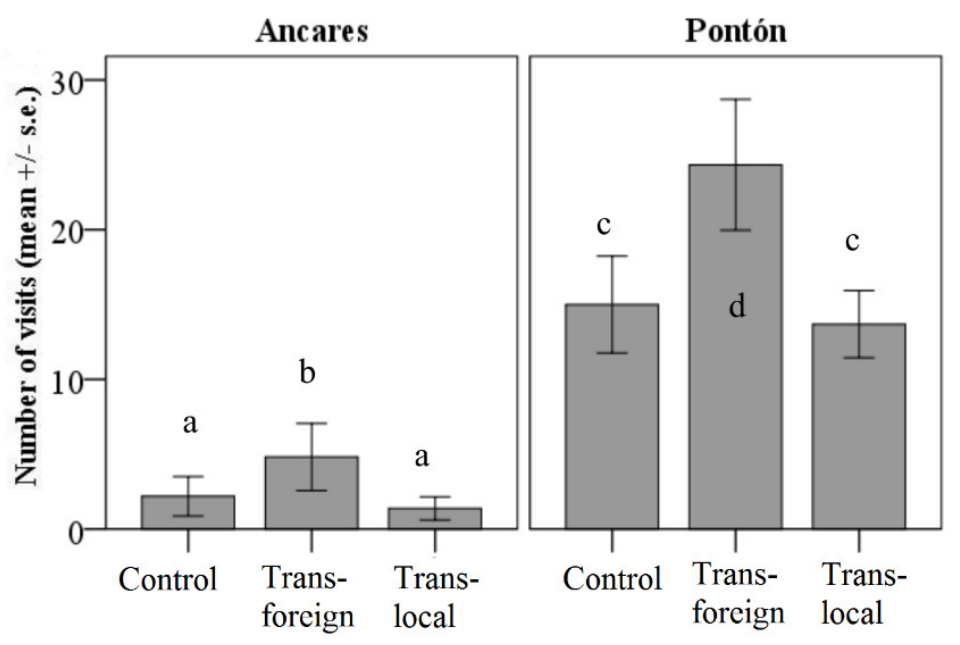

(B) Group 3 (Bombus pratorum, ancaricus and lapidarius)

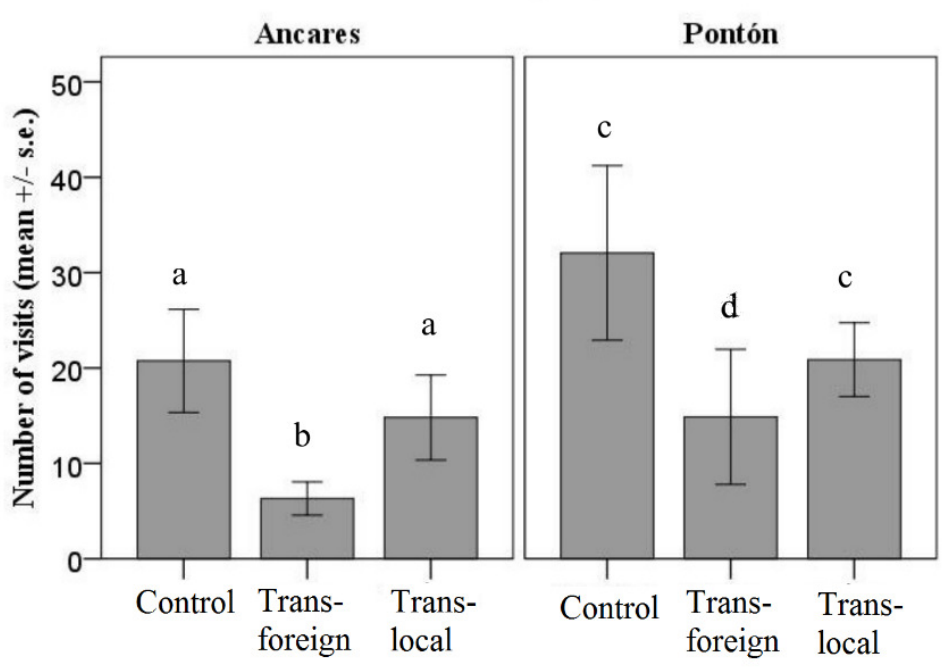

515

516 Figure 4: Number of floral visits per plant per 30 min (mean \pm standard error) by two

517 bumblebee groups (A) group 1: Bombus terrestris; (B) group 3: B. pratorum, B. soroensis

518 ancaricus, B.lapidarius decipiens; depending on the locality at northern Spain (Ancares, the

519 orange morph population; and Pontón, the yellow morph population) and the experimental

520 treatment (control, local transplant, foreign transplant). 
521 Abbreviations: Trans-foreign (foreign transplant); Trans-local (local transplant). Different letters

522 indicate statistical differences among treatments $(P<0.01)$. 